\title{
Schistosoma haematobium Infection and the Gynecological and Obstetric Effects on Girls and Women: A Short Note
}

\author{
Maria A Grácio* \\ Institute of Hygiene and Tropical Medicine / New University of Lisbon, Lisbon, Portugal
}

${ }^{\star}$ Corresponding author: Professor Maria A Grácio, Institute of Hygiene and Tropical Medicine / New University of Lisbon, Rua da Junqueira 100, 1348-008 Lisbon, Portugal; Email: mameliahelm@ihmt.unl.pt

Received: October 28, 2018; Accepted: November 14, 2018; Published: November 22, 2018;

\section{Short Commentary}

Schistosoma haematobium (blood fluke) has a complex life cycle, involving freshwater snails as intermediate hosts and humans as definitive host.

Humans are passive victims of this parasite, not as occurs with other parasites that have insects as vectors that are actively introduced when the insects have a blood meal, when humans enter into fresh water they are infected from snails parasitized with S. haematobium in the form of numerous infective cercariae. These cercariae swim in the water and penetrate the human skin.. After penetration, the cercariae are known as schistosomulae. These migrate and develop into mature adult schistosome worms in and around the vesical plexus, and occasionally in the rectal region, the mesenteric portal system and ectopic sites [1]. Then, the parasite can have several negative effects on female health, and here our objective is to alert medical practitioners of the gynecological and obstetric effects on girls and women. Considering the mode of transmission of S. haematobium, we must recognize the fact that the high risk of infection occurs in regions where the human population is exposed to snails where there is a lack of a water canalization system, and basic sanitation. In general, these are in conditions of severe poverty. In Africa where these situations are frequent schistosomiasis caused by S. haematobium is endemic, and girls and women are more exposed to infection because of their domestic work, bathing and fishing and agricultural, activities that in several African countries are especially attributed to girls and women.. Accordingly [2] women suffer considerably from female genital schistosomiasis that causes infertility, preterm labor, anemia, menstrual disorders, and dyspareunia. Also infected pregnant women have low birth weight infants, and an increased infant and maternal mortality rates. In Africa approximately 10 million women have schistosomiasis in pregnancy [3-5]. Schistosomiasis has been detected in the placenta and in newborns thus confirming congenital infection. Data suggest that infected women have a higher rate of spontaneous abortions and a higher risk for ectopic pregnancies [6,7].

Concerning schistosomiasis treatment [8], Praziquantet (PZQ) was made available in 1979 and has been the mainstay of schistosomiasis control programs for decades. PZQ was never studied in pregnant and lactating women and was, therefore, designated as a "pregnancy class B" drug. In this class, the drugs are presumed to be safe based on animal studies but lack safety data from studies in pregnant women. In practice, this has led to the withholding of treatment for pregnant and lactating women in most schistosomiasis endemic countries.

In [8] we have a good and recent article on PZQ for the treatment of schistosomiasis during human pregnancy. The authors cite in their conclusion: "based on recent evidence of the safety of praziquantel in human pregnancy, we recommend that, in areas with endemic schistosomiasis, women of reproductive age, including pregnant and breastfeeding women, be treated with PZQ either individually, in local antenatal clinics, or in mass drug administration".

Considering our personal knowledge acquired during our scientific activities on S. haematobium / schistosomiasis carried out in Guinea Bissau [9], we found that many girls and women had a history of menstrual disorders, infertility and spontaneous abortions.

Final conclusion: in view of the negative effects of S. haematobium on physical health here related and, certainly, on psychological health of girls and women, treatment with PZD may be ministered to pregnant and lactating girls and women.

Keywords: Schistosoma haematobium; Girls; Women; Gynecology; Obstetric; Praziquantel

\section{References}

1. Eddington GM, Nwabuelo I, Junaid TA (1975) The pathology of schistosomiasis in Ibadan Nigeria, with special reference to the appendix, brain, pancreas and genital organs. Trans R Soc trop Med Hyg 69: 153-156.

2. Nour NM (2010) Schistosomiasis: health effects on women. Rev Obstet Gynecol winter; 3(1): 28-32.

3. Friedman JF, Mital P, Kanzaria HK, Olds GR, Kurtis JD (2007) Schistosomiasis and pregnancy. Trends in Parasitology 23(4): 159-164.

4. Slegrist D, Slegrist-Obimpeh P (1992) Schistosoma haematobium infection in pregnancy. Acta Trop 50: 317/322

5. Helling-Giese G, Kjetland EF, Gundersen SG et al (1996). Schistosomiasis in woman: manifestations in the upper reproductive tract. Acta Trop 62: 225-238.

6. Bahrain S, Alatassi H, Slone SP, O'Connor DM (2006) Tubal gestation and schistosomiasis: a case report. J Reprod Med 51: 595-598.

7. Laxma VV, Adamson B, Mahmood T (2008). Recurrent ectopic pregnancy due to Schistosoma haematobium. J Obstet Gynaecol 461-462.

8. Friedman JF, Olveda RM, Mirochnich MH, Bustinduy AL, Elliott (2018). Praziquantel for the treatment has of schistosomiasis during human pregnancy. Bull World Health Organ. Jan 1; 96(1): 59-61. 
Maria A Grácio (2018) Schistosoma Haematobium Infection and the Gynecological and Obstetric Effects on Girls and Women: A Short Note

9. Grácio MA, Nhaque AT, Rollinson D (1987-1991). Schistosomiasis in Guinea Bissau, contract TS2 -0205- Science and Technology for Development, Second program, European Commission, vol 2 - Parasitology: 239-247.

Citation:

S Maria A Grácio (2018) Schistosoma Haematobium Infection and the Gynecological and Obstetric Effects on Girls and Women: A Short Note. Integr Gyn Obstet J Volume 1(3): 1-2. 